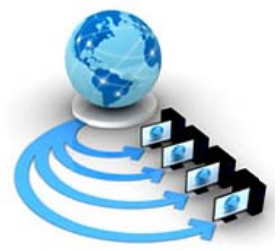

Volume 9, No. 1, January-February 2018

International Journal of Advanced Research in Computer Science

CASE STUDY

Available Online at www.ijarcs.info

\title{
BONE FRACTURE IDENTIFICATION - A CASE STUDY BASED ON STATISTICAL MODELLING
}

\author{
Shanthi Raju Lanka \\ Department of Information Technology \\ GITAM Institute of Technology, GITAM \\ Visakhapatnam, India
}

\author{
Srinivas Yarramalle \\ Department of Information Technology \\ GITAM Institute of Technology, GITAM \\ Visakhapatnam, India
}

\begin{abstract}
With the increase in the number of cases pertaining to medical diseases, medical image processing became one of the most important sub-areas in the field of image processing. Many applications of medical image processing are highlighted in the earlier works. However, in this article, we confine towards the study of fracture detection using model-based approaches. The medical data of the bone fracture cases are obtained from the x-rays available at MVP Hospital and the automation of fracture detection methodology was carried out on a real-time medical data by understanding the human skeletal system, bone and fractures. The data is tested using metrics like a signal to noise ration, MSE, image fidelity.
\end{abstract}

Keywords: Human Skeletal system, fracture, model-based techniques, performance evaluation, and metrics.

\section{INTRODUCTION}

The continuing progress in the number of medical cases has led towards the development of automated tools to assist the diseased patients and help in proper diagnosis. As this cases are increasing enormously, led to the development of sophisticated medical analysis tools and also propelled the area of medical imaging. Medical imaging process bundle with algorithms and techniques for the assessment of medical diseases and also the deeper analysis of the diseases in several medical domains ranging from trauma, orthopedic, neuro and other cardiac-related diseases. These technologies are proven to be worthwhile in aiding both the patients and medical practitioners to exactly know the insight of the diseases and the diagnostic process available thereof. Among the available tools for medical diagnosis, in this article, we confine towards the development of tools and techniques for effectual identification of trauma-related diseases, in particular for effective identification of fractures and bone alignments. This developed methodology helps to minimize the time complexity beyond the identification of the fracture in the human body and also helps to interpret the degree of alignment.

The human body is made up of bones and the joints. Skeleton is a hard framework of the human body which is built up using bones. Almost all the parts are connected to each other using the bone structure. Every skeleton system performs several major functions including support, movement, protection, storage, endocrine regulation and blood cell production. Every human skeleton encompasses three main vital components viz., bones, cartilages and joints. Among these components, bones are considered to be caring the most weight-bearing parts of the human body and are considered to be the main source of strength to the human skeleton. Since the strength of the body is entirely taken care by the bones, it is mandated to withhold the bone structure and the bones more aptly. A small hairline crack may hamper the human skeleton and thereby the stability and the mobility will be at stake. Therefore effective identification of the fracture is to be clearly emphasised estimated. Several methodologies were laid by the researchers in this area of research [1], [2], [3], [4], [5]. However, due to the diversity of the shapes, most of the models presented in the literature may not yield appropriate results during the estimation and classification of a bone deformity.

Every bone in the human skeleton will be grouped among the following few class labels

i) Long bones, ii) Short bone, iii) flat bone, iv) irregular bones and v) sesamoid bones

Each of these bones is having a separate functionality and they differ in size and shape from anatomy to anatomy and completely dependent on the basis of bone development. There are three general categories of bone development namely membranous bones, cartilaginous and member cartilaginous bones [9], [10], [11]. Since the structure of the bones and the anatomy of the bone structure is not uniform, at exhibits different forms and shapes, it is customary to develop methodologies that can identify the shape of the bone structure pertaining to different anatomies. And hence in this article, a methodology is developed by underlying the bone analysis. For this purpose, we have considered the statistical mixture model based on Bivariate Generalized Gaussian Mixture Model (BGGMM). The rest of the paper is structured as follows. Section 2 of the paper deals with the symptoms and causes of bone fractures, in section 3 BGGMM is highlighted. The dataset considered is presented in section 4 of the paper, experimentation and the results derived using performance metrics are highlighted in section 5 , performance evaluation is discussed in section 6 and the concluding section 7 summarizes the article.

\section{SYMPTOMS AND CAUSES}

The signs and symptoms with respect to a bone fracture changes from individual to individual. However there are most common symptoms that are being witnessed in each and every case which include; bruising, swelling, change in colour, bent in angle, difficulty in movement, granting sensation, and pain. In the open end fracture, patients may witness bleeding in particular when there is a fracture at the long bones such as pelvis etc [6], [7], [8]. In which case a patient also suffers from dizziness and possesses a pale look. 
In most of the cases if a patient is suffering from a bone ailment he may be treated with

i) immobilization, ii) metal plates and screws, iii) platter casts, iv) external fixates and v) Healing

\section{BIVARIATE GENERALIZED GAUSSIAN MiXTURE MODEL}

Most of the fractures that are highlighted are mostly nonhomogenous and are asymmetric in nature. To analyze the type of fracture, one need to consider distributions that can cater both symmetric and asymmetric nature of the distributions. Bivariate Generalized Gaussian Mixture Model is one among such distributions. Hence, in this article, we have considered Bivariate Generalized Gaussian Mixture Model.

The probability density function of the distribution is given by

$$
\mathrm{f}_{\mu, \sigma, \lambda}(\mathrm{x})=\frac{2}{\sigma} \quad\left(\frac{\mathrm{x}-\mu}{\sigma}\right) \cdot \Phi\left(\lambda \frac{\mathrm{x}-\mu}{\sigma}\right)
$$

Where $\mu \quad R, \sigma>0$ and $\lambda \quad R$ represents the location, scale and shape parameters respectively. Where and $\Phi$ denote the probability density function and the cumulative density function of the standard normal distribution. The maximum and minimum intensity of pixels within the image regions are denoted by ' $a$ ' and ' $b$ '. Truncating the data between these limits helps to minimize the image space. Using this concept, Truncating equation (1) between these limits ' $a$ ' and ' $b$ ' we have

\section{DATASET CONSIDERED}

In order to portray the proposed method, we have considered real-time dataset from MVP Hospital, Visakhapatnam having images of deformities near leg segment, hand, arm, elbow, thigh and each of these images are pre-processed such that they are free from noise. Each image is acquired using an x-ray and all these images are processed with the support of medical practitioner.

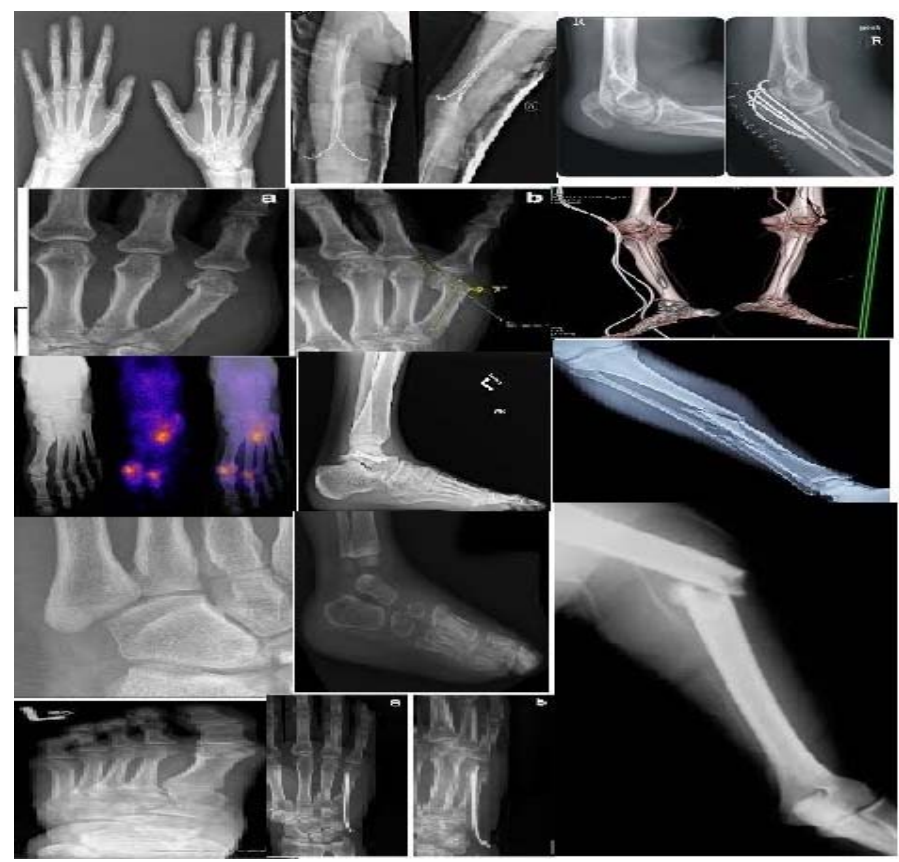

Figure 1. Dataset Considered.

\section{EXPERIMENTATION AND RESULTS}

In order to portray to present model, we have considered a dataset presented in the above section for the experimental purpose. The experimentation is carried out in MATLAB environment and for training purpose, we have considered 75 images and for testing 15 images were considered. Each of the images is eliminated from the noise and the features of these images were considered as inputs. Since we have considered the Bivariate model, we have considered the symptom and the deformity in the consideration and these two features are given as input to the model highlighted in section 3 of the article. The corresponding PDF are therefore obtained against each of these images considered for training as well as testing. The image PDF's are collected and stored and against a query image the relevant PDF are correlated and the similar images are retrieved. This methodology will be well suited for specific cases like identification of the deformity based on the x-ray image even at rural health care centres because the probability of a particular symptom can be correlated with that of the symptoms and probabilities in the database to have a concreteness in the disease. The methodology is tested and the results are compared with that of the existing models based on GMM and are presented in the following table 1 of the article

Table I. Experimental Results

\begin{tabular}{|c|c|c|c|c|}
\hline Image & $\begin{array}{l}\text { Quality } \\
\text { Metrics }\end{array}$ & MSSGMM & $\begin{array}{l}\text { Standard } \\
\text { Limits }\end{array}$ & $\begin{array}{c}\text { Standard } \\
\text { Criteria }\end{array}$ \\
\hline & $\begin{array}{l}\text { Average } \\
\text { Difference }\end{array}$ & 0.00073 & -1 to 1 & Closer to 1 \\
\hline & $\begin{array}{l}\text { Maximum } \\
\text { Difference }\end{array}$ & 0.01893 & -1 to 1 & Closer to 1 \\
\hline & $\begin{array}{l}\text { Image } \\
\text { Fidelity }\end{array}$ & 0.95843 & 0 to 1 & Closer to 1 \\
\hline & $\begin{array}{l}\text { Mean } \\
\text { Squared } \\
\text { Error }\end{array}$ & 0 & 0 to 1 & Closer to 0 \\
\hline & $\begin{array}{l}\text { Signal to } \\
\text { Noise } \\
\text { Ratio }\end{array}$ & $\infty$ & $-\infty$ to $\infty$ & $\begin{array}{l}\text { As big as } \\
\text { possible }\end{array}$ \\
\hline & $\begin{array}{l}\text { Average } \\
\text { Difference }\end{array}$ & $\begin{array}{l}\text { 6.00644E- } \\
05\end{array}$ & -1 to 1 & Closer to 1 \\
\hline & $\begin{array}{l}\text { Maximum } \\
\text { Difference }\end{array}$ & 0.010577 & -1 to 1 & Closer to 1 \\
\hline & $\begin{array}{l}\text { Image } \\
\text { Fidelity }\end{array}$ & 0.989414 & 0 to 1 & Closer to 1 \\
\hline & $\begin{array}{l}\text { Mean } \\
\text { Squared } \\
\text { Error } \\
\end{array}$ & 0 & 0 to 1 & Closer to 0 \\
\hline & $\begin{array}{l}\text { Signal to } \\
\text { Noise } \\
\text { Ratio }\end{array}$ & $\infty$ & $-\infty$ to $\infty$ & $\begin{array}{l}\text { As big as } \\
\text { possible }\end{array}$ \\
\hline & $\begin{array}{l}\text { Average } \\
\text { Difference }\end{array}$ & 0.00027 & -1 to 1 & Closer to 1 \\
\hline & $\begin{array}{l}\text { Maximum } \\
\text { Difference }\end{array}$ & 0.00042 & -1 to 1 & Closer to 1 \\
\hline & $\begin{array}{l}\text { Image } \\
\text { Fidelity }\end{array}$ & 0.99892 & 0 to 1 & Closer to 1 \\
\hline & $\begin{array}{l}\text { Mean } \\
\text { Squared } \\
\text { Error }\end{array}$ & 0 & 0 to 1 & Closer to 0 \\
\hline & $\begin{array}{l}\text { Signal to } \\
\text { Noise } \\
\text { Ratio }\end{array}$ & $\infty$ & $-\infty$ to $\infty$ & $\begin{array}{l}\text { As big as } \\
\text { possible }\end{array}$ \\
\hline
\end{tabular}




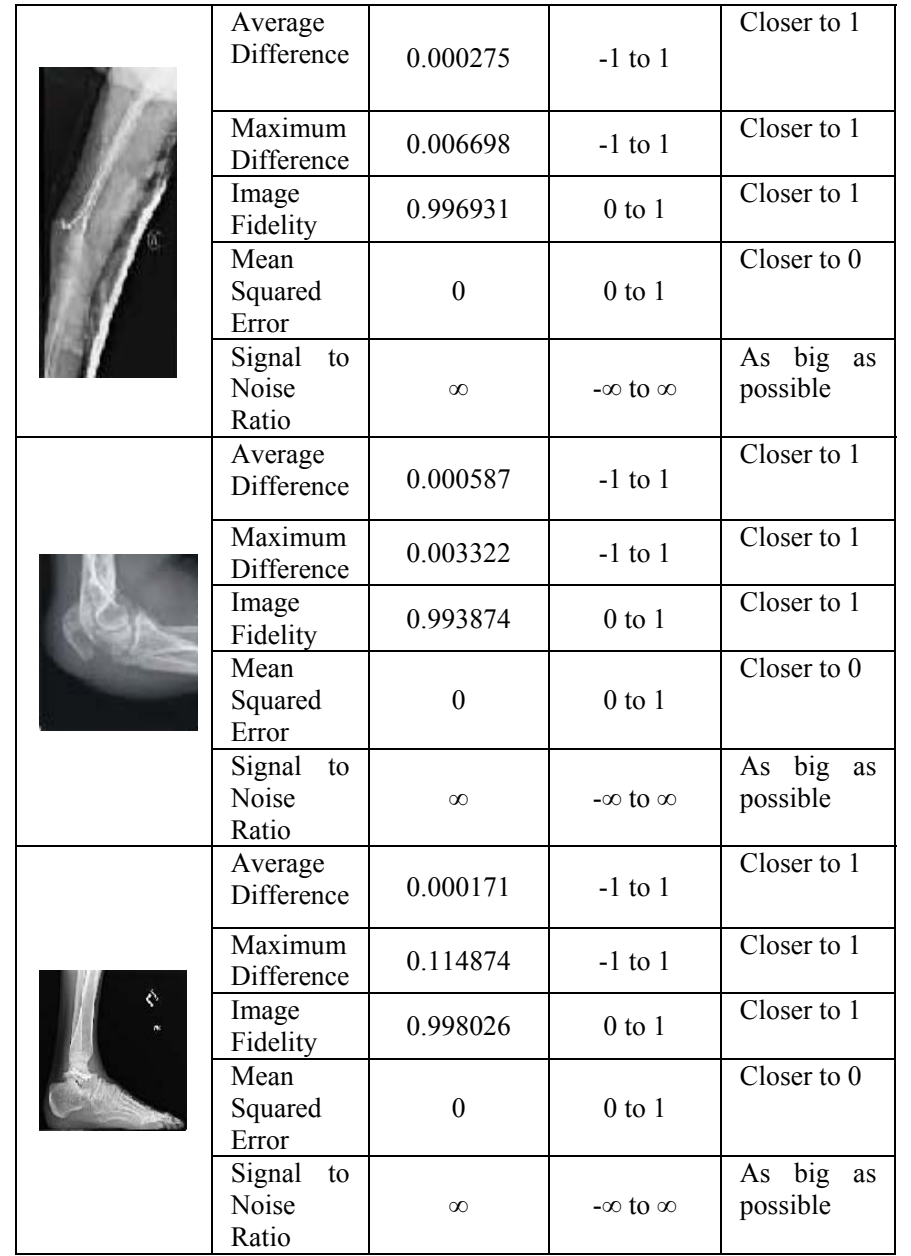

\section{PERformance EVALUATION}

In order to test the effectiveness of the model several quality testing metrics like average difference, maximum difference, image fidelity, mean squared error, signal to noise ratio. The formulas for calculation are presented in table 2 . The methodology tested against these metrics are tabulated and presented in the above table.

Table II. Quality Metrics

\begin{tabular}{|c|c|}
\hline $\begin{array}{l}\text { Quality } \\
\text { Metrics }\end{array}$ & Formula to Evaluate \\
\hline $\begin{array}{l}\text { Average } \\
\text { Difference }\end{array}$ & $\begin{array}{l}\qquad \frac{\sum_{j=1}^{M} \sum_{k=1}^{N}[F(j, k)-\hat{F}(j, k)]}{M N} \\
\text { Where M, N are image matrix Rows and } \\
\text { Columns }\end{array}$ \\
\hline $\begin{array}{l}\text { Maximum } \\
\text { Distance } \\
\end{array}$ & $\operatorname{Max}\{|F(j, k)-\hat{F}(j, k)|\}$ \\
\hline Image Fidelity & $\begin{array}{l}\quad 1-\left[\frac{\sum_{j=1}^{M} \sum_{k=1}^{N}[F(j, k)-\hat{F}(j, k)]^{2}}{\sum_{j=1}^{M} \sum_{k=1}^{N}[F(j, k)]^{2}}\right] \\
\text { Where } \mathrm{M}, \mathrm{N} \text { are image matrix Rows and } \\
\text { Columns }\end{array}$ \\
\hline $\begin{array}{l}\text { Mean Squared } \\
\text { Error }\end{array}$ & $\begin{array}{l}\frac{1}{M N} \frac{\sum_{j=1}^{M} \sum_{k=1}^{N}[O\{F(j, k)\}-O\{\hat{F}(j, k)\}]^{2}}{\sum_{j=1}^{M} \sum_{k=1}^{N}[O\{F(j, k)\}]^{2}} \\
\text { Where M, N are image matrix Rows and } \\
\text { Columns }\end{array}$ \\
\hline $\begin{array}{l}\text { Signal to } \\
\text { Noise Ratio }\end{array}$ & $20 \log _{10}\left(\frac{M A X_{I}}{\sqrt{M S E}}\right)$ \\
\hline
\end{tabular}

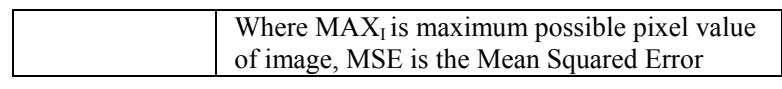

\section{CONCLUSION}

In this article, a methodology was presented for highlighting the identification of fractures based on a bivariate statistical modelling approach. Since we have considered two variants into consideration the article is assumed to generate fruitful results and can be underlined from the above table 1 . The results derive are compared to that of the existing models based on GMM and from the developed results it can be understood that a proposed method outperforms the existing model.

\section{REFERENCES}

[1] Ahmad Oryan, Somayeh Monazzah, Amin Bigham-Sadegh, "Bone injury and healing Biology", Biomed Environment Science, Vol 28(1), 2015 pp 57-71.

[2] Frederic Shapiro, "Bone Development and its relation to fracture repair. The role of mesenchymal osteoblasts and surface osteoblasts", European Cells and Materials Vol. 15, 2008 pp 53-76.

[3] Balasubramanian Thiagarajan, Venkatesan Ulaganathan, "Fracture Nasal Bones", Otolaryngology online journal, Vol 3 (1), 2013, pp 1-16.

[4] Anu T C, Mallikarjunaswamy M.S, Rajesh Raman, "Detection of Bone Fracture using Image Processing Methods", International Journal of computer applications, 2015, pp 6-9.

[5] Vijaykumar V, Vanathi P, Kanagasabapathy P, "Fast and efficient algorithm to remove Gaussian noise in digital images". IAENG International Journal of Computer Science, Vol 37(1), 2010.

[6] Samuel Febrianto Kurniawan, I Ketut Gede Darmaputra, A.A Kompiang Oka Sudana, "Bone Fracture Detection Using OpenCV", Journal of Theoretical and Applied Information Technology, Vol 64(1), 2014, pp 249-254.

[7] Tanudeep Kaur, Anupam Garg, "Bone Fraction Detection using Image Segmentation", International Journal of Engineering Trends and Technology, Vol 36(2), 2016, pp 82-87.

[8] Malashree, G.Narayana Swamy, "Automatic Detection of Radius of Bone Fracture", International Research Journal of Engineering and Technology, Vol 4(6), 2017, pp 17961799.

[9] Irfan Khatik, "A Study of Various Bone Fracture Detection Techniques", International Journal of Engineering and Computer Science, Vol 6(5), 2017, pp 21418-21423.

[10] Ö. Öztürk and H. Kutucu, "Detection of bone fractures using image processing techniques and artificial neural networks," 2017 International Artificial Intelligence and Data Processing Symposium (IDAP), Malatya, 2017, pp. 15, doi: 10.1109/IDAP.2017.8090311.

[11] Bandyopadhyay O., Biswas A., Bhattacharya B.B. (2014) Long-Bone Fracture Detection in Digital X-ray Images Based on Concavity Index. In: Barneva R.P., Brimkov V.E., Šlapal J. (eds) Combinatorial Image Analysis. IWCIA 2014. Lecture Notes in Computer Science, vol 8466. Springer, Cham, doi: 10.1007/978-3-319-07148-0_19. 